\title{
Small Propeller and Rotor Testing Capabilities of the NASA Langley Low Speed Aeroacoustic Wind Tunnel
}

\author{
Nikolas S. Zawodny* and Henry H. Haskin ${ }^{\dagger}$ \\ NASA Langley Research Center, Hampton, VA, 23681
}

The Low Speed Aeroacoustic Wind Tunnel (LSAWT) at NASA Langley Research Center has recently undergone a configuration change. This change incorporates an inlet nozzle extension meant to serve the dual purposes of achieving lower freestream velocities as well as a larger core flow region. The LSAWT, part of the NASA Langley Jet Noise Laboratory, had historically been utilized to simulate realistic forward flight conditions of commercial and military aircraft engines in an anechoic environment. The facility was modified starting in 2016 in order to expand its capabilities for the aerodynamic and acoustic testing of small propeller and unmanned aircraft system (UAS) rotor configurations. This paper describes the modifications made to the facility, its current aerodynamic and acoustic capabilities, the propeller and UAS rotor-vehicle configurations to be tested, and some preliminary predictions and experimental data for isolated propeller and UAS rotor configurations, respectively. Isolated propeller simulations have been performed spanning a range of advance ratios to identify the theoretical propeller operational limits of the LSAWT. Performance and acoustic measurements of an isolated UAS rotor in hover conditions are found to compare favorably with previously measured data in an anechoic chamber and blade element-based acoustic predictions.

\section{Nomenclature}

$C_{T} \quad$ Propeller thrust coefficient, $T / \rho_{\infty} n^{2} D_{p}^{4}$

$c_{0} \quad$ Ambient speed of sound, $\mathrm{m} / \mathrm{s}$

$D_{b} \quad$ Nacelle body diameter, $\mathrm{m}$

$D_{\text {nozzle }} \quad$ Tunnel inlet diameter, $\mathrm{m}$

$D_{p} \quad$ Propeller diameter, $\mathrm{m}$

$\Delta f \quad$ Narrowband spectra frequency resolution, $\mathrm{Hz}$

$J \quad$ Propeller advance ratio, $U_{\infty} / n D_{p}$

$M_{\infty} \quad$ Freestream Mach number, $U_{\infty} / c_{0}$

$n \quad$ Propeller rotation rate, revolutions per second

$R \quad$ Rotor tip radius, $\mathrm{m}$

$S t_{D} \quad$ Strouhal number based on ref. diameter, $f D / U_{\infty}$

$T \quad$ Propeller/rotor thrust, N

$U_{\infty} \quad$ Tunnel freestream velocity, $\mathrm{m} / \mathrm{s}$

$\bar{u} \quad$ Mean measured velocity, $\mathrm{m} / \mathrm{s}$

$\alpha \quad$ Propeller angle of attack, deg.

$\rho_{\infty} \quad$ Ambient air density, $\mathrm{kg} / \mathrm{m}^{3}$

$\Omega \quad$ Propeller/rotor rotation rate, revolutions per minute (RPM)

$\theta \quad$ Observer angle rel. rotor plane, deg.

$\theta_{o} \quad$ Source emission angle rel. forward flight direction, deg.

\footnotetext{
*Research Aerospace Engineer, Aeroacoustics Branch, Member AIAA; nikolas.s.zawodny@nasa.gov

$\dagger$ Facility Engineer, Aeroacoustics Branch, Member AIAA; henry.h.haskin@nasa.gov
} 


\section{Introduction}

The emergence of alternative aircraft vehicle concepts in recent years has presented unique technical and regulatory challenges to the Federal Aviation Administration (FAA). The considerable increase in the presence of and market for unmanned aircraft systems (UAS) has required the FAA to institute regulatory policies to address this increased demand. However, in order to make informed regulatory decisions on UAS certifications, technical data must be acquired on the performance capabilities of such vehicles. Also, a better understanding of the potential impacts that these vehicles will have on the civilian population is required. The acoustic characteristics of these vehicles are one important aspect of community impact which requires experimental investigation.

The NASA New Aviation Horizons initiative presents a 10-year plan to design, test, and implement new technologies including fuel, emissions, and noise-reducing technologies on new civil aircraft platforms, or Xplanes. ${ }^{1}$ One of these vehicles is the X-57 Maxwell, which is meant to serve as the platform to demonstrate the potential benefits associated with a general aviation-sized aircraft using distributed electric propulsion. In addition to the needs associated with UAS vehicle certifications, experimental data are also needed in order to meet the goals of this initiative. To acquire these data, a wind tunnel facility capable of efficiently acquiring both performance and acoustic research data applicable to these different vehicle/propulsion systems for tool validation is needed.

\section{The LSAWT}

The LSAWT is an open-circuit free jet wind tunnel that provides a simulated free-flight air stream to an upper limit Mach number of $M_{\infty}=0.32$. The free jet exhausts into a 10.4-m long test cell with a cross section of $5.2 \mathrm{~m} \times 5.2 \mathrm{~m}$. The floor, ceiling, and walls are treated with $0.61-\mathrm{m}$ tall acoustic fiberglass wedges. This acoustic treatment ensures anechoic facility characteristics down to a cut-on frequency of approximately 200 $\mathrm{Hz}$. The facility is equipped with a 28-element linear array of $6.35 \mathrm{~mm}$-diameter B\&K model 4939 free-field microphones. This array is located along one of the test cell upper corners, and spans the entire length of the test chamber.

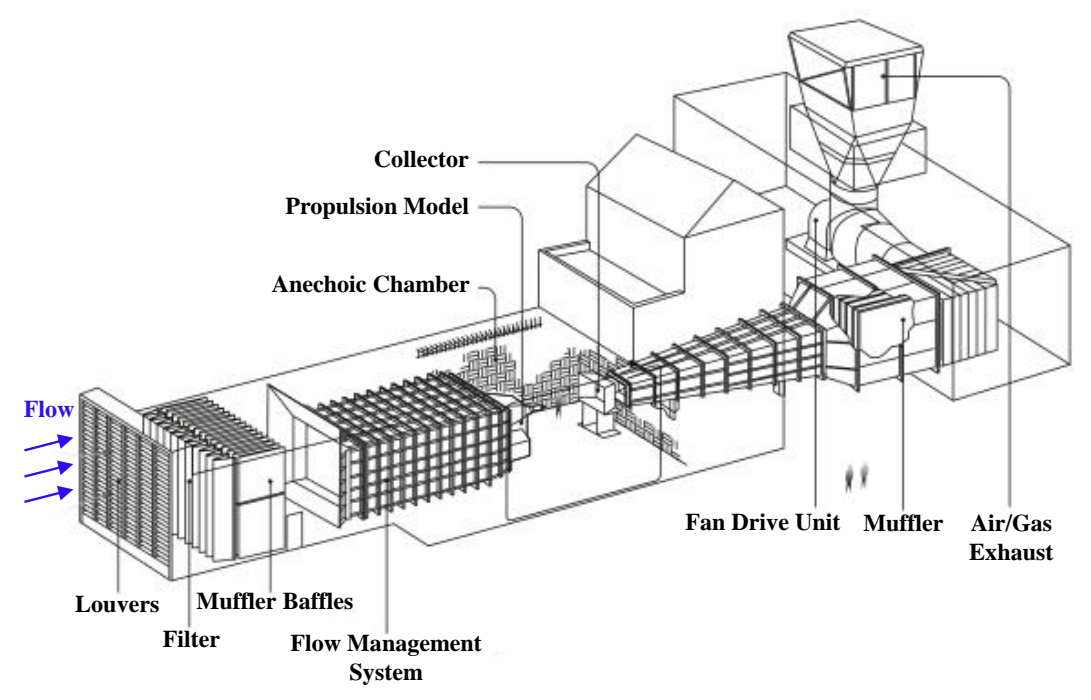

Figure 1. Isometric view schematic of the LSAWT.

\section{A. Historical and Current Configurations}

Historically, the LSAWT has been utilized to simulate realistic forward flight conditions of commercial and military aircraft jet engines in an anechoic environment. This configuration consists of an inlet nozzle of square cross-section and a through-duct, floor-mounted dual stream jet engine simulator (JES). The facility has been utilized extensively for multiple decades of jet aeroacoustics research. With the JES due for recertification and requiring removal, the opportunity was taken to improve the facility capability utilizing the 
clean test section of this anechoic wind tunnel. ${ }^{2}$

The primary modifications that have been applied to the LSAWT are the removal of the JES and installation of a new inlet nozzle extension, along with re-pitching of the wind tunnel fan blades for lower tunnel velocities. The new nozzle extension is $1.946 \mathrm{~m}$ long, and undergoes a transition from the historical square inlet to a circular cross-section of larger diameter, the dimensions of which are provided in Table 1. Removal of the JES has allowed for the placement of different test articles in the open jet test section. These articles are positioned in the test cell via a modular model test stand (MTS). Figure 2 shows images of the test cell historical and current configurations with representative installed test articles. The modular nature of the small propeller and rotor test stand allows for more efficient re-installation of the JES and original wind tunnel nozzle when the jet noise testing capability is required.

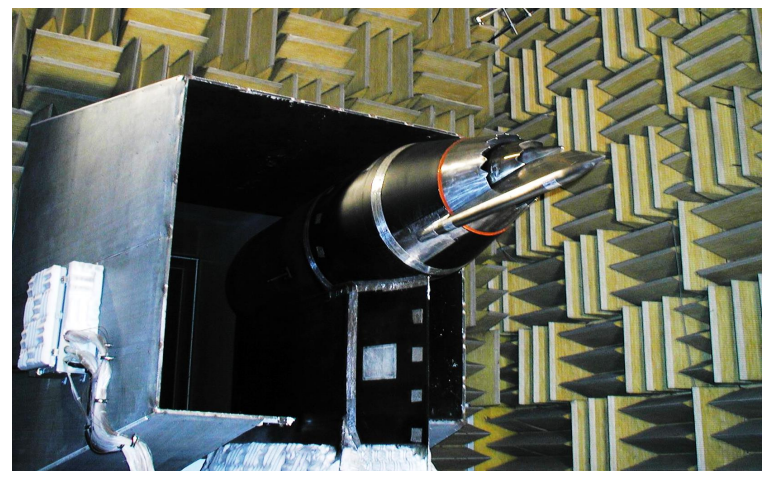

(a) Historical (JES) Configuration
Table 1. Comparison of historical and current LSAWT test cell configuration parameters.

\begin{tabular}{|lll|}
\hline Parameter & Historical & Current \\
\hline Test Section Length, m & 6.121 & 5.588 \\
Inlet Nozzle Width, m & $1.435^{*}$ & $1.930^{* *}$ \\
Lower-End Tunnel Mach \# & 0.100 & $0.045^{\dagger}$ \\
Upper-End Tunnel Mach \# & 0.320 & $0.140^{\dagger}$ \\
Test Article(s) & JES & MTS \\
\hline
\end{tabular}

*Square cross-section

** Circular cross-section

$\dagger$ Minimum fan blade pitch settings

Figure 2. LSAWT test articles associated with historical and current tunnel configurations.

The current configuration of the LSAWT is meant to accommodate a variety of testing platforms spanning from electric propellers and small rotary-wing UAS components to full vehicles. These test articles are positioned within the test section via the mobile MTS mentioned previously, a visual component breakdown of which is provided in Fig. 3. As this figure shows, the MTS is equipped with hardware allowing both pitch and yaw movements, housed within an airfoil fairing assembly. Test articles are mounted to the MTS via a sting arm. Details of the different test configurations are provided in Section III.

\section{B. Test Section Characteristics}

Mean flow field characteristics of the LSAWT empty test section were acquired at several locations within the tunnel inlet nozzle and in the open jet of the test section. A twelve-port boundary layer probe was used to measure the axial growth of the boundary layer along the length of the inlet nozzle extension centerline, while a 32-port pitot rake was used for both continued boundary layer measurements in the nozzle exit region and for core flow and shear layer velocity measurements in the open jet test section. Freestream turbulence measurements were also acquired using a single component hot-wire probe at several axial and

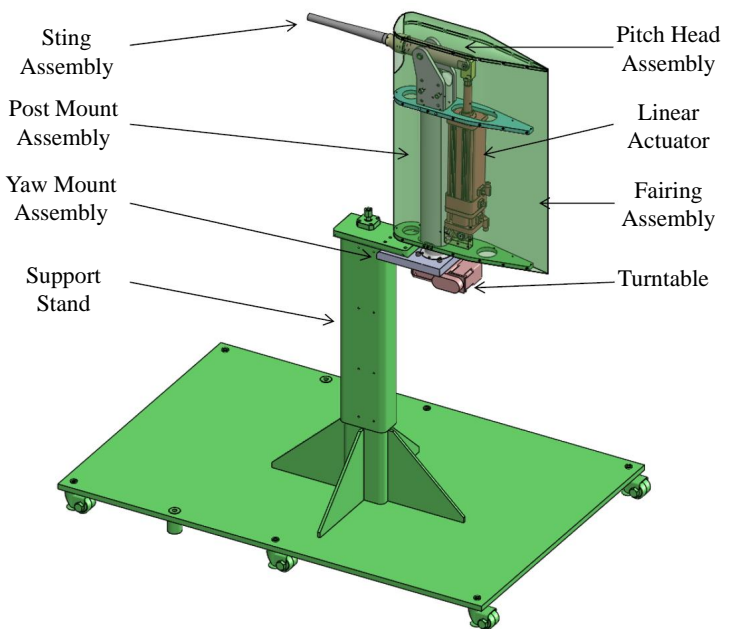

Figure 3. Components of the mobile model test stand. 
lateral locations downstream of the inlet trailing edge. This was done in order to more clearly identify regions of the core flow suitable for placement of test models. A summary of the measurement conditions is provided in Table 2. A two-axis traverse system was used to laterally traverse the pitot rake at each indicated axial measurement location in an effort to map out a full lower quadrant of the core flow and shear layer regions.

Table 2. Flow measurement parameters in LSAWT test cell.

\begin{tabular}{|l|c|c|}
\hline Measurement Parameter & Axial Locations, $\left(x / D_{\text {nozzle }}\right)^{*}$ & Tested Mach \#s \\
\hline Nozzle Boundary Layer & $-0.922,-0.530,-0.050$ & $0.045,0.050,0.060$ \\
& & $0.070,0.080,0.090$ \\
& & $0.100,0.110,0.120$ \\
\hline \hline Shear Layer, Core Flow & $0.066,0.855,2.803$ & $0.045,0.070,0.110$ \\
\hline \hline Freestream Turbulence & $0.066,0.461,0.855$ & $0.045,0.050,0.060$ \\
& & $0.070,0.080,0.090$ \\
& & $0.100,0.110,0.120$ \\
\hline
\end{tabular}

* Negative values denote locations upstream of nozzle trailing edge, positive values downstream

\section{Nozzle Boundary Layer Behavior}

Figure 4 presents boundary layer data acquired at three different axial locations along the bottom surface of the LSAWT nozzle centerline for a freestream Mach number of $M_{\infty}=0.110$. Data for the two locations furthest upstream $\left(x / D_{\text {nozzle }}=-0.922,-0.530\right)$ were acquired using the boundary layer probe, while that for the location furthest downstream $\left(x / D_{\text {nozzle }}=-0.050\right)$, was acquired using both the boundary layer probe and pitot rake.

The results show a considerable increase in boundary layer thickness along the length of the inlet nozzle. This is due to the inlet nozzle expansion. It is also worth noting the apparent emergence of an adverse pressure gradient near the nozzle exit, evidenced by the secondary velocity "knee" between $y=10$ and $50 \mathrm{~mm}$. While the measurement resolution of the boundary layer probe is too coarse to reliably define a boundary layer thickness for the two further upstream measurement locations, vertical traversing of the pitot rake in increments of $2.54 \mathrm{~mm}$ provides a more reliable boundary layer definition close to the nozzle exit (NE) plane. This value was computed to be $\delta_{N E}=104 \mathrm{~mm}$ based on the conventional definition of $\delta=y\left(u / U_{\infty}=0.99\right)$. Note that the profile results for the other tested freestream Mach numbers are very similar to the data shown in Fig. 4.

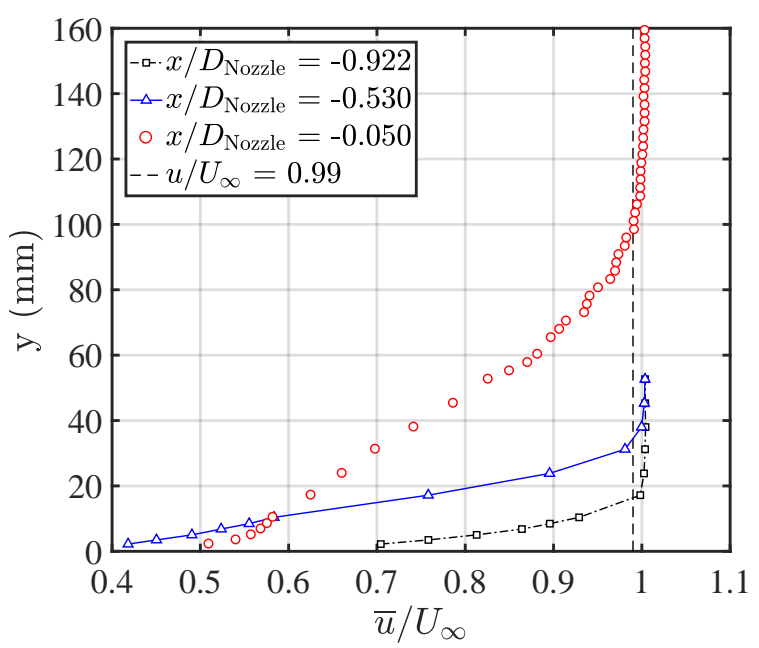

Figure 4. Boundary layer data at different axial locations in LSAWT inlet nozzle. $\left(M_{\infty}=0.110\right)$

\section{Core Flow Contraction/Shear Layer Development}

Characterization of the extent of the core flow in the test section is important in determining acceptable test article size and performance upper limits. The installation of lifting objects such as high-lift airfoils and propellers can have drastic impacts on the core flow including core flow contraction, jet deflection, and test cell recirculation effects. Therefore, a lower quadrant of the LSAWT test cell open jet was surveyed using the 32-element pitot rake previously mentioned. Results of these surveys for the three previously mentioned axial measurement locations (see Table 2) for a freestream Mach number of $M_{\infty}=0.110$ are provided in Fig. 5. The data clearly show both the contraction of the core flow as well as the thickening of the shear layer with increasing downstream distance. The data also show deviation of the core flow shape from circular near the nozzle exit (Fig. 5(a)) to more of a diamond-type profile near the jet collector (Fig. 5(c)).

Quantifications of the mean core flow size and shear layer locations were done using the data shown in Fig. 5. The mean core flow radius, $\bar{r}_{C}$, was approximated by identifying the physical measurement 


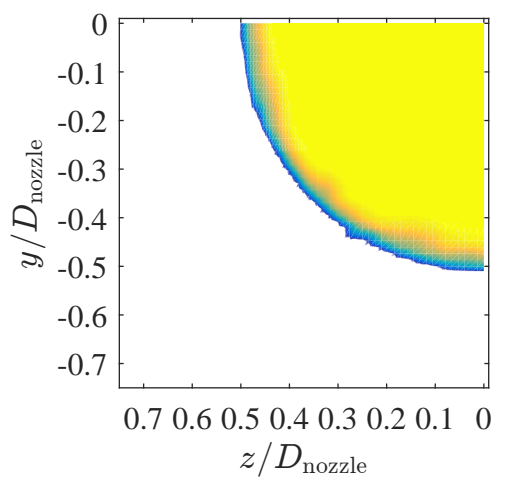

(a) $x / D_{\text {nozzle }}=0.066$

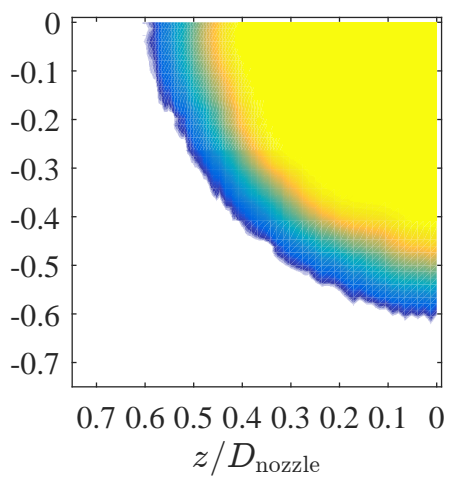

(b) $x / D_{\text {nozzle }}=0.855$

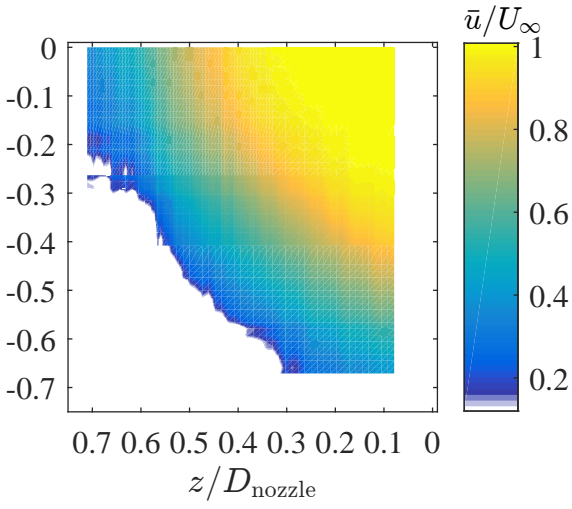

(c) $x / D_{\text {nozzle }}=2.803$

Figure 5. Core flow/shear layer surveys of LSAWT test section lower quadrant. $\left(M_{\infty}=0.110\right)$

locations that correspond to a nominal lower limit value $\bar{u} / U_{\infty}=0.99$. An envelope of values ranging from $0.981 \leq \bar{u} / U_{\infty} \leq 0.999$ was considered, based on the bias uncertainty of the pressure measurement system. In a similar manner, the mean shear layer radial location, $\bar{r}_{S L}$, was approximated by physical locations corresponding to $\bar{u} / U_{\infty}=0.50$. Again, based on the bias uncertainty of the pressure measurement system, an envelope of values ranging from $0.480 \leq \bar{u} / U_{\infty} \leq 0.520$ were considered. The results of these calculations are shown in Fig. 6. As this figure shows, both the shear layer and core flow extents display reasonable linear behavior. The linear curve fits that were generated from the shear layer location and core radius data had determination coefficients (r-squared values) of 0.991 and 0.992, respectively. Furthermore, the linear curve fit of the mean shear layer growth was found to have a slope that corresponds to a shear layer half spread-angle of $\psi_{1 / 2} \approx 2.1^{\circ}$. It is worth noting that slight deviations from linear trends are not surprising since this analysis does not account for the apparent changing shape

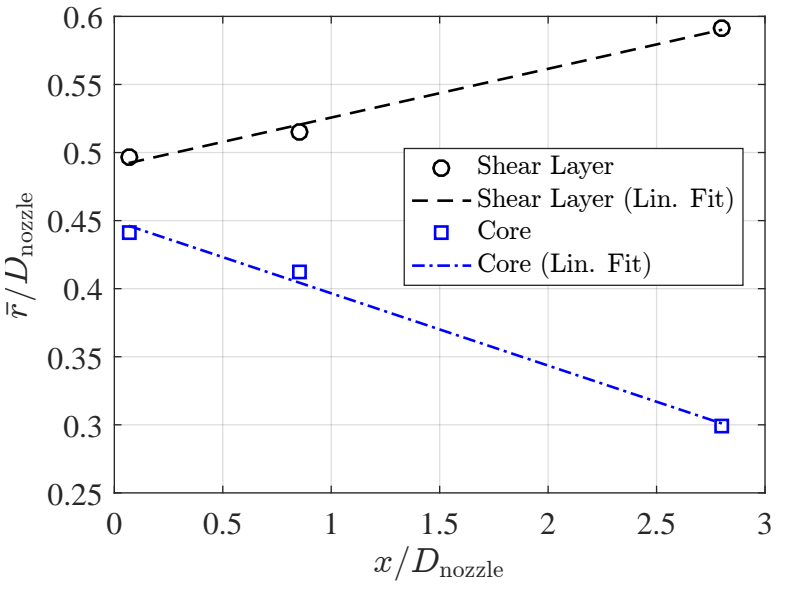

Figure 6. Mean shear layer growth and core contraction of LSAWT open jet. $\left(M_{\infty}=0.110\right)$ of the core flow region with increasing downstream distance.

\section{Freestream Turbulence}

Axial turbulent velocity measurements were acquired in the LSAWT empty test section using a Dantec Type 55 constant temperature anemometer (CTA) hot-wire probe, which was powered using a Dantec Streamline signal conditioner. The probe was positioned in the LSAWT using the same two-axis traverse system discussed previously. The probe was positioned at different lateral locations corresponding to $z / D_{\text {nozzle }}=$ $0,0.132,0.263$, and 0.395 for each of the axial measurement locations listed in Table 2. The probe was calibrated using a pressurized plenum-nozzle apparatus that provided calibration velocities in the range of $0.035 \leq M_{\text {cal }} \leq 0.2$. A total of 15 velocities within this velocity range and a static condition were used to construct a fourth order polynomial calibration curve. An additional correction ${ }^{3}$ was applied to the raw output hot-wire probe voltage, $E_{w}$, according to deviations from the reference ambient temperature $\left(T_{r}\right)$ condition recorded at the time of probe calibration:

$$
E_{w, \mathrm{corr}}=E_{w}\left[\frac{T_{w}-T_{r}}{T_{w}-T_{\infty}}\right]^{1 / 2},
$$

where $T_{w}$ and $T_{\infty}$ represent the hot-wire and freestream temperatures, respectively. This calibration procedure yielded hot-wire mean freestream velocity measurements (measured along the tunnel centerline) within 
$3 \%$ of that measured by the LSAWT nozzle pressure measurement system for all conditions reported in this paper. Figure 7 presents turbulent velocity spectra for a range of freestream Mach numbers at an axial location of $x / D_{\text {nozzle }}=0.461$. Specifically, Fig. 7 (a) and Fig. 7 (b) present the respective dimensional and non-dimensionalized spectra. The data of Fig. 7(b) were generated by normalizing the velocity spectra by the square of the measured freestream velocity, $U_{\infty}^{2}$. They are also plotted versus Strouhal number based on the inlet nozzle diameter, $S t_{D_{\text {nozzle }}}=f * D_{\text {nozzle }} / U_{\infty}$. This non-dimensionalization is seen to appropriately collapse the velocity spectra across a Strouhal number range of $0.6 \leq S t_{D_{\text {nozzle }}} \leq 100$.

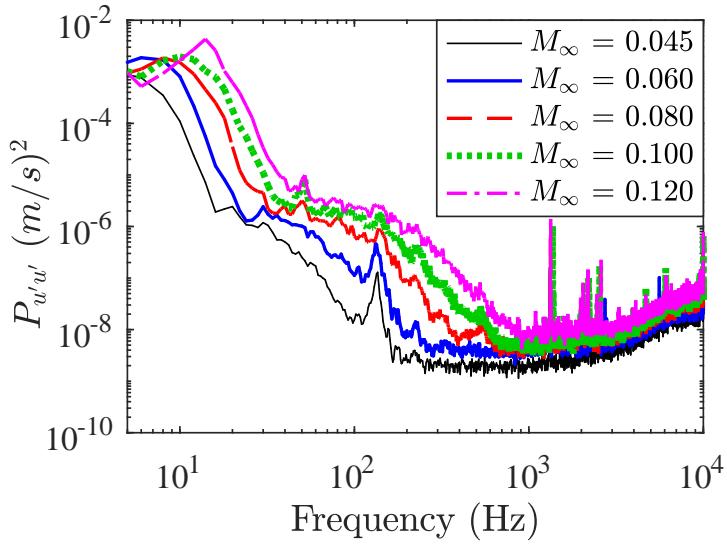

(a) Dimensional Spectra

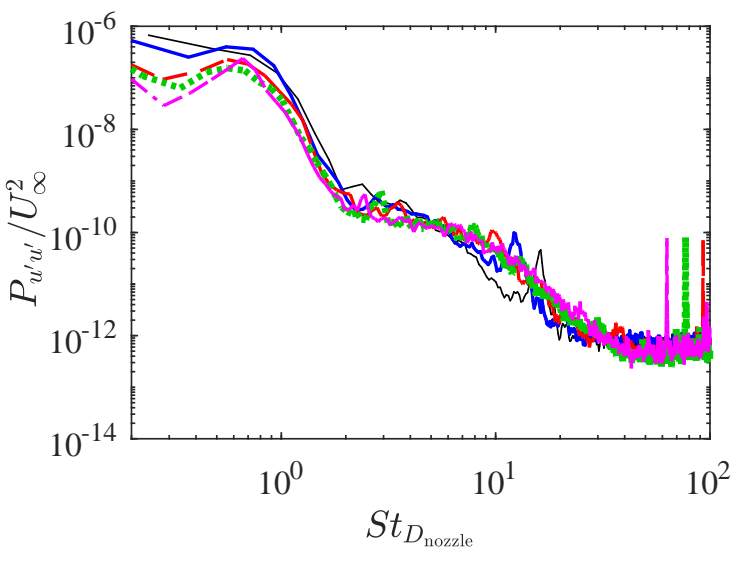

(b) Non-dimensional Spectra

Figure 7. Turbulent velocity spectra at tunnel centerline at an axial location of $x / D_{\text {nozzle }}=0.461$ for a range of tunnel freestream Mach numbers.

Freestream turbulence intensities were estimated by integrating the velocity turbulence spectra across a frequency range of $1.0 \leq S t_{D_{\text {nozzle }}} \leq 100$ according to Eq. 2 .

$$
T I=100 \times \frac{\sqrt{\int_{f(S t=1.0)}^{f(S t=100)}\left(P_{u^{\prime} u^{\prime}} / \Delta f\right) d f}}{U_{\infty}} .
$$

The low-end cut-on frequency was chosen because it corresponds to a length scale equivalent to the inlet nozzle diameter, which is believed to be a suitable upper-end turbulence length scale of consideration. Table 3 presents a summary of turbulence intensities computed at the different axial and lateral measurement locations within the LSAWT open-jet for a freestream condition of $M_{\infty}=0.1$. As expected, the data in the table clearly show increases in computed turbulence intensity in both axial (flow) and lateral directions within the open-jet test section. It is worth noting that the majority of the energy that contributes to these turbulence intensity values occurs at frequencies below $25 \mathrm{~Hz}$. These results provide additional restrictions on core flow quality, rather than strictly depending on the mean flow surveys discussed previously. In other words, although the mean core flow limits shown in Fig. 6 imply a core flow region spanning at least $0.8^{*} D_{\text {nozzle }}$ to an axial extent of $x / D_{\text {nozzle }}=0.855$, the turbulence measurements indicate that there may be a need for a much more restrictive core flow region for test article placement. This is important when considering test articles such as full multi-copter vehicles or multiple propellers in a distributed propulsion configuration. Future rotor and propeller testing is planned to determine an appropriate turbulence intensity cut-off for such testing.

Table 3. Turbulence intensities (\%) at different locations in LSAWT open-jet at $M_{\infty}=0.1$.

\begin{tabular}{|l|rrrr|}
\hline$x / D_{\text {nozzle }}$ & $z / D_{\text {nozzle }}=0$ & 0.132 & 0.263 & 0.395 \\
\hline 0.066 & 0.014 & 0.017 & 0.047 & 0.385 \\
0.461 & 0.026 & 0.045 & 0.161 & 0.992 \\
0.855 & 0.054 & 0.101 & 0.320 & 1.610 \\
\hline
\end{tabular}

\section{Facility Noise Levels}

While installation of the new larger round inlet nozzle in the LSAWT offers the benefits of lower possible freestream velocities and a larger core flow field, it also offers acoustic challenges. It is worth noting that the 
flow collector immediately upstream of the tunnel diffuser had not changed from the historical to the current configuration. As a result, the nozzle-collector area ratio has increased from 0.35 to 0.50 . This coupled with the increased boundary layer thickness at the nozzle trailing edge, and the resulting open-jet shear layer thickness, can cause a considerable portion of the open jet flow to escape the collector and recirculate in the test cell. Another factor requiring consideration is the relatively lower frequency ranges of interrogation and lower sound pressure levels associated with full-scale UAV and small propellers as compared to the scaled JES articles most recently tested in the LSAWT. ${ }^{4,5}$ Therefore, the axial location of the collector was varied to reduce the potential levels of recirculation and ascertain its effect on the facility noise levels. An experimental windscreen was also utilized on one of the linear array microphones near the collector face $\left(\theta_{o}=137.5^{\circ}\right)$ to qualitatively determine how much of the empty facility noise is microphone self-noise due to flow recirculation. This windscreen was designed to provide the benefits of a conventional foam-style windscreen, however with the added benefit of improved acoustic transparency.

Figure 8(a) presents empty test section acoustic spectra for an uncorrected observer location of $\theta_{o}=40^{\circ}$, relative to the upstream direction for a range of collector positions. This microphone was chosen to illustrate the facility noise at a location that is least likely to be affected by flow recirculation. As this figure shows, the initial collector location of $\Delta X=0 \mathrm{~mm}$ (which corresponds to the historical JES-installed tunnel configuration) portrays a pronounced broad spectral hump spanning an approximate frequency range of $500 \leq f \leq 800 \mathrm{~Hz}$. Gradually shifting the collector upstream is seen to reduce both the frequency range and spectral amplitude of this hump. Furthermore, Fig. 8(b) shows spectra for the same conditions at an observer angle of $\theta_{o}=137.5^{\circ}$. These results show a trend similar to that of the upstream microphone for

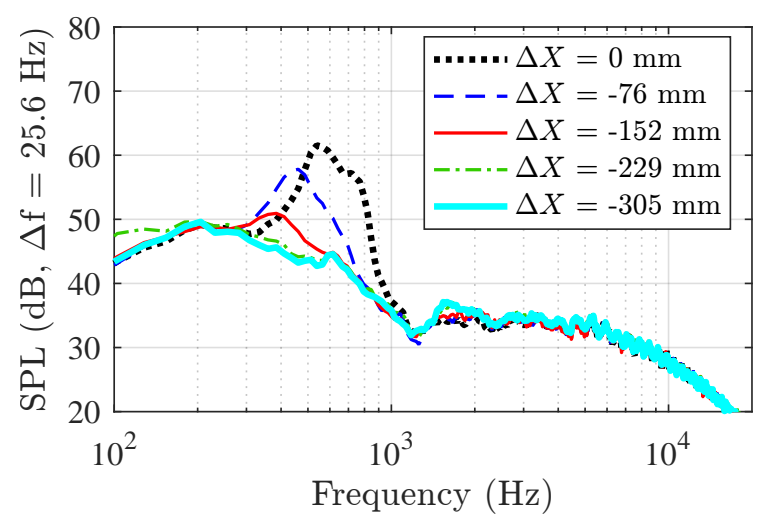

(a) $\theta_{o}=40^{\circ}$

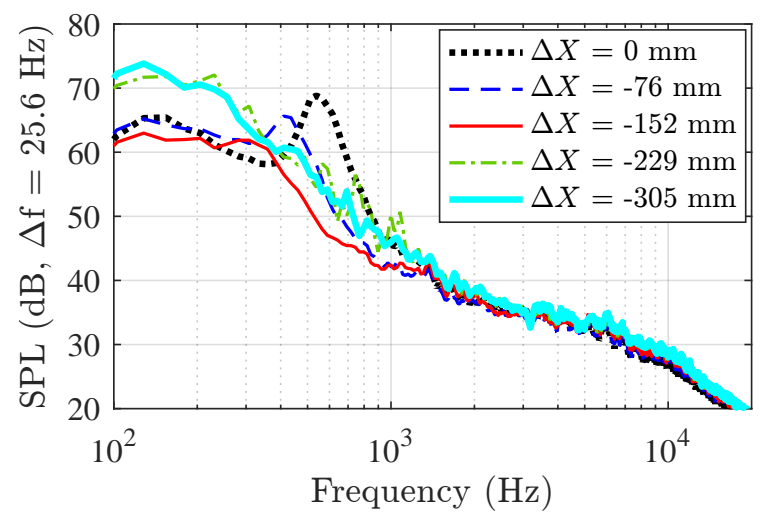

(b) $\theta_{o}=137.5^{\circ}$

Figure 8. Sample empty test section microphone acoustic spectra for different jet collector positions at $M_{\infty}=$ 0.100 . Note: negative $\Delta X$ values represent upstream increments; microphone at $\theta=137.5^{\circ}$ covered with windscreen; data high-pass filtered at frequency of $100 \mathrm{~Hz}$.

the first three collector positions. The latter two collector positions corresponding to $\Delta X=-229$ and -305 $\mathrm{mm}$, however, show a prominent increase in broadband noise across a frequency range of $100 \leq f \leq 250$ Hz. It is important to note that this microphone is treated with a windscreen for these measurements. It is also interesting to note that there is very little variation in the spectral content for both microphones above a frequency of $1.5 \mathrm{kHz}$, regardless of the collector position. This is evidence that this high-frequency broadband noise is likely due to turbulence generated by the inlet nozzle. These results indicate that a collector location in the vicinity of $\Delta X=-152 \mathrm{~mm}$ upstream of the diffuser entrance may prove to be a suitable lower noise testing configuration. This will be verified in the future by measuring the acoustic performance of this windscreen concept on all the linear array microphones.

The performance of the experimental windscreen on a microphone near the flow collector is provided in Fig. 9 with a comparison to a conventional foam windscreen provided by Brüel \& Kjaer (B\&K Model UA-0459). It is worth noting that testing the foam windscreen required the installation of the microphone protective grid, whereas the cases of no windscreen and experimental windscreen installed utilized the bare microphone with no protective grid installed. Figure 9(a) displays acoustic spectra measured by the microphone both with and without the windscreens installed for the case of a broadband airball source with no tunnel flow. These results are very encouraging since they show very little indication of the experimental 


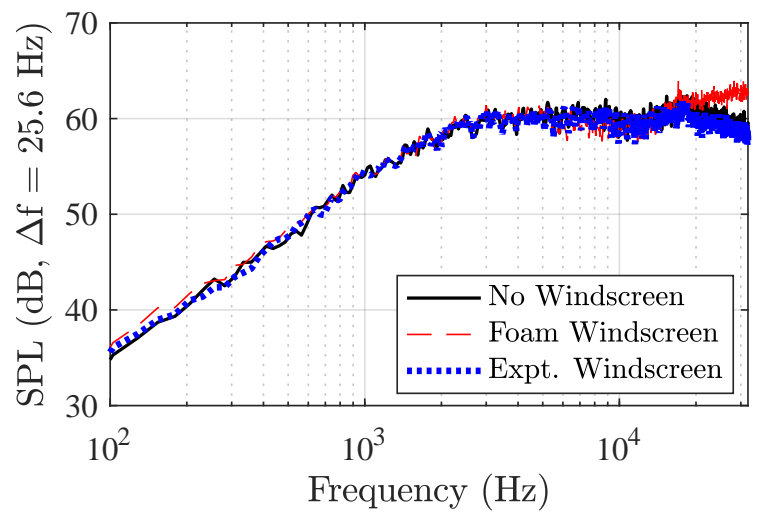

(a) Broadband Source (No Flow)

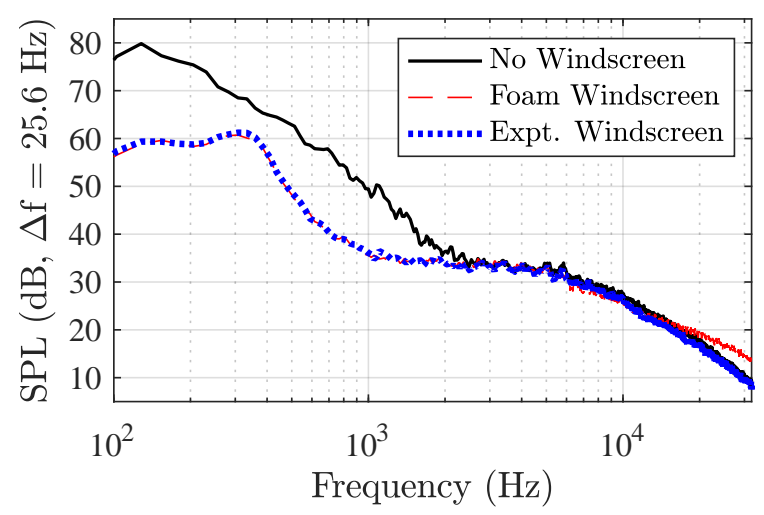

(b) $M_{\infty}=0.100$

Figure 9. Effects of experimental windscreen on microphone acoustic spectrum for cases of no tunnel flow with a broadband noise source and with tunnel flow at $M_{\infty}=0.100$. Note: $\theta_{o}=137.5^{\circ}$; data high-pass filtered at $100 \mathrm{~Hz}$.

windscreen presence for the frequency range shown. There are amplitude deviations noticeable, however, for the case of the foam windscreen at frequencies above $15 \mathrm{kHz}$. While this frequency is at the upper end of interest for cases of full-scale acoustic measurements, the possibility of testing scaled propellers could warrant the need for reliable spectral amplitude measurements at and above this frequency. Figure 9(b) further shows the effects of the windscreen installation on the same microphone for the case of flow in the empty LSAWT test section. These results show a considerable reduction in measured facility noise ranging from 7 to 20 $\mathrm{dB}$ across a frequency range of $100 \leq f \leq 1,500 \mathrm{~Hz}$. These results are further encouraging since they show that the experimental windscreen performs just as well as the foam windscreen at reducing the recirculation induced self-noise at low frequencies. Furthermore, the high-frequency spectral amplitude deviations of the foam windscreen are also evident in this figure. A more in-depth frequency response characterization and further development of the experimental windscreen are planned for the immediate future.

\section{Testing Hardware}

As mentioned previously in Section II.A, the current LSAWT configuration is intended to accommodate test articles encompassing small propellers and small UAS platforms (individual components, as well as full vehicles). The following sections provide an overview of the testing hardware associated with these different configurations.

\section{A. Electric Propeller Testing}

A cut-away view of the propeller testing rig is provided in Fig. 10. The five-bladed propeller ${ }^{6}$ is powered by a $152-\mathrm{mm}$ outer diameter, 20-pole in-running brushless motor. Propeller performance data will be acquired using a six-component strain gage balance mounted to the back motor surface, along with a triaxial accelerometer for monitoring vibrations and for setting propeller geometric angles of attack. This hardware is housed within a rapid-prototyped nacelle fairing of conical shape, which is also outfitted with an axial distribution of static pressure taps. Instrumentation and power wiring are routed out from the propeller assembly via a cylindrical conduit. Finally, the leading edge of the assembly consists of a front-vented spinner nose cone. The spinner is vented in order to provide cooling air from the freestream flow to the brushless motor. Tests will be done to determine the acoustic effects of having a vented versus non-vented spinner present on the assembly.

In addition to testing a single isolated propeller, more complex configurations are planned in the future. These encompass a propeller-wing assembly as well as multiple simultaneous propellers to simulate a distributed electric propulsion configuration. ${ }^{7}$ These more complex configurations are intended to measure noise resulting from respective propeller wake-wing impingement and propeller-propeller interaction source mechanisms. Visualizations of the three configurations are provided in Fig. 11. Note that the propeller-wing 


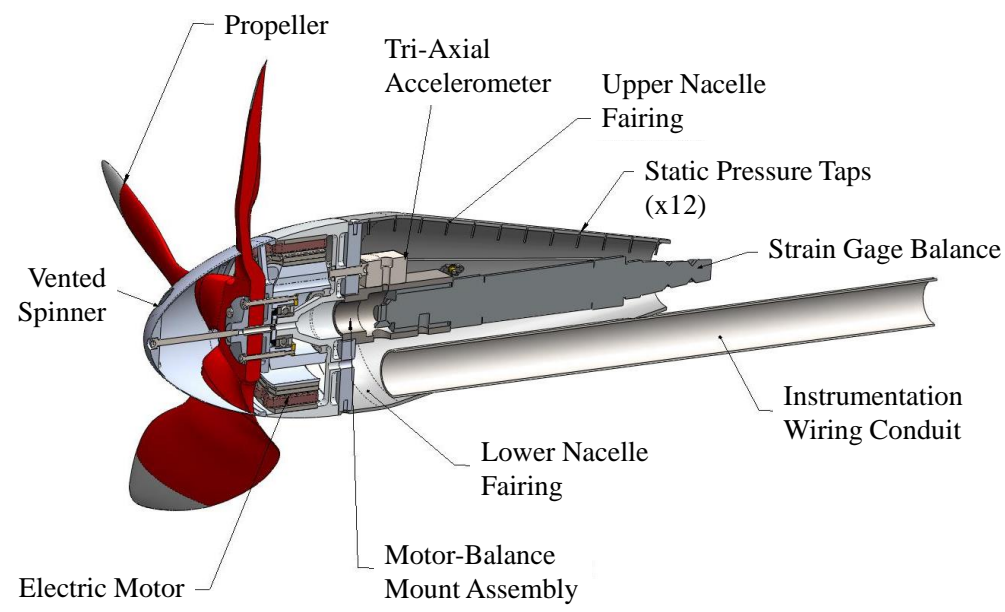

Figure 10. Cut-away view of propeller assembly.

test setup of Fig. 11(b) utilizes an airfoil model spanning beyond the shear layer of the test section and is supported by a two-axis traverse system. This traverse system will be used to vary the propeller-wing spacings in both streamwise and vertical directions. Furthermore, the multiple-propeller test setup of Fig. 11(c) consists of three propellers mounted on a triple-sting mount. This triple-sting will allow variable propeller spacings in both streamwise and lateral directions. Testing of three propellers is of interest since it allows for measuring the acoustic impact of an inner-nested propeller in a distributed propulsion configuration. It is worth noting that the propeller-wing and multiple-propeller configurations utilize reduced scale propellers. Testing of scaled propellers for these configurations is deemed necessary for several reasons. First and foremost, it is important that the components of the propeller-wing setup are of appropriate relative scale to one another. This ensures appropriate Mach and Reynolds number scaling behavior. Additional reasons involve practical considerations related to the wind tunnel itself. The size of the wing, for example, must be such that the resulting lift and drag loads generated are manageable by the supporting traverse system. Finally, testing propellers in an open-jet facility is a challenging task that could result in a prominent core flow contraction depending on the thrust levels generated by the propeller apparatus. ${ }^{8}$ Testing of multiple propellers could potentially result in encroachment of the shear layer - and associated turbulent velocity fluctuations - into the propeller disk areas, which in turn could yield misleading propeller performance and acoustic results. Therefore, the testing of scaled propellers assists in reducing the chance of shear layer flow contamination. More details about how the propeller apparatus will be physically scaled and performance-limited based on the LSAWT facility capabilities are described in Section IV.A.

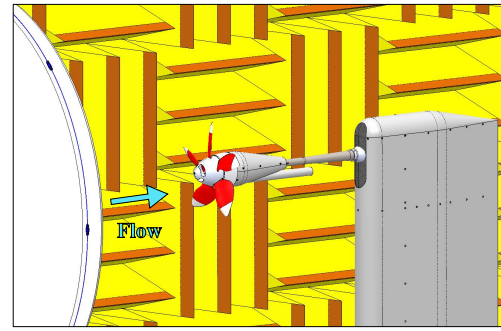

(a) Isolated Propeller

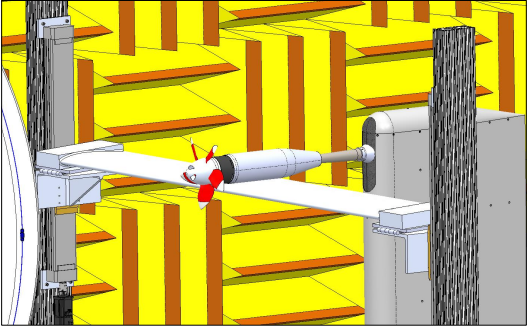

(b) Propeller-Wing Assembly

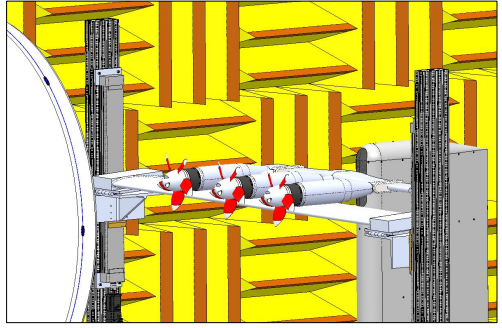

(c) Multiple-Propeller Assembly

Figure 11. Renderings of different propeller configurations. Note: multiple-propeller assembly configuration (c) will be tested both with and without wing model present. 


\section{B. UAS Vehicle/Component Testing}

The mobile MTS will be reconfigured to mount both single rotor-motor systems and full multi-copter UAS platforms. Figure 12 presents visualizations and component breakdowns of these configurations. In addition to far-field acoustics, the test setup is also able to be configured for acquiring rotor/vehicle performance data using multi-axis load cells. Section IV.B provides static performance and acoustic data for a small isolated rotor in hover conditions as a demonstration of these capabilities.

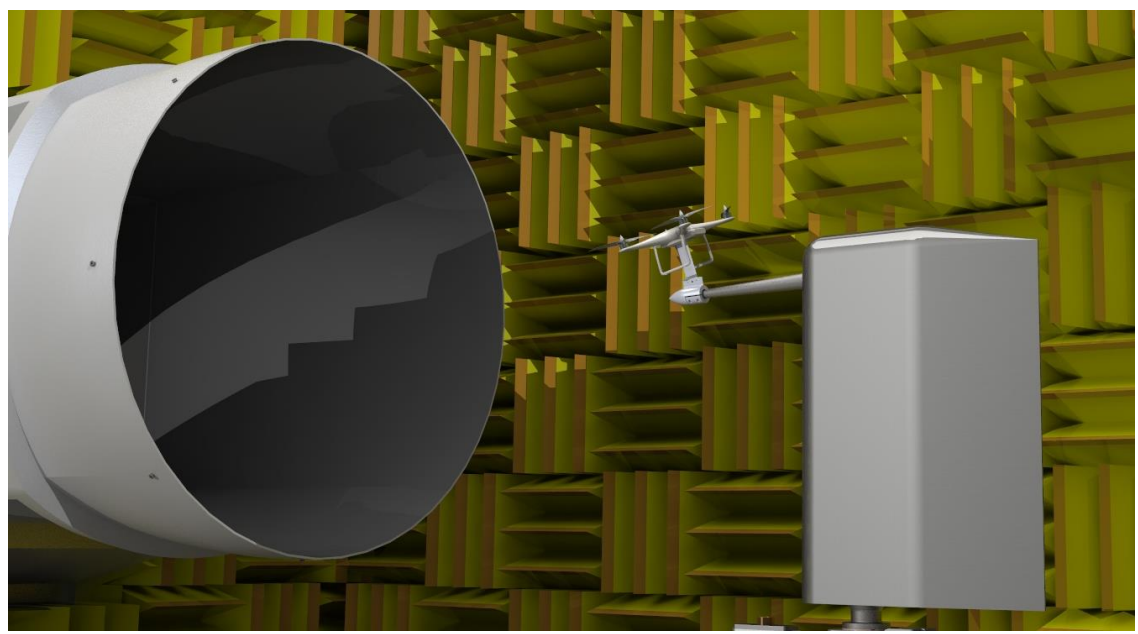

(a) Small Quad-copter UAS Configuration

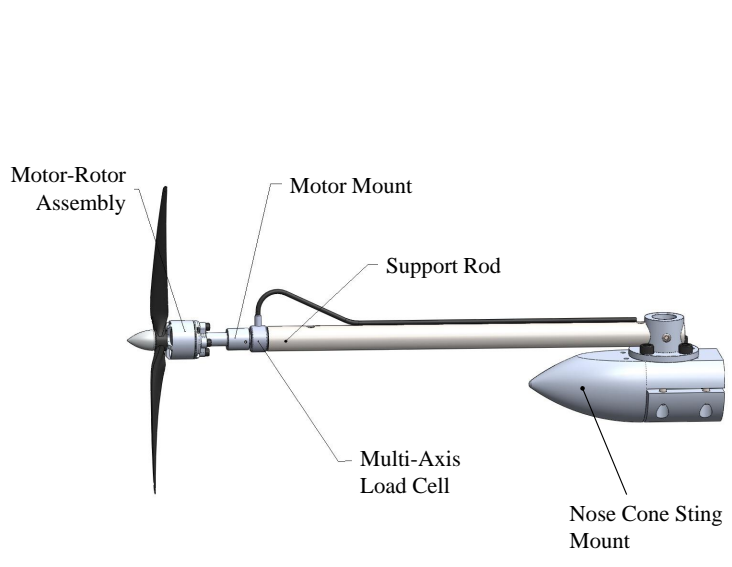

(b) Single Propeller/Rotor

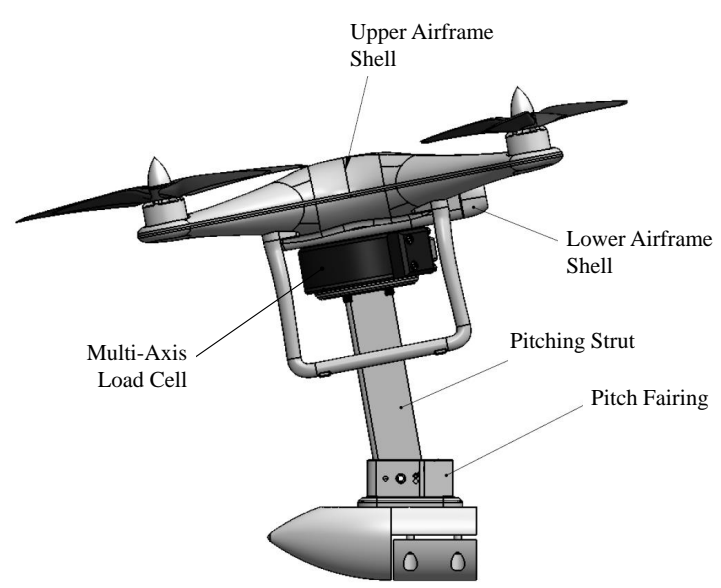

(c) Full Vehicle

Figure 12. Visualization of UAS testing configuration and associated hardware in LSAWT.

\section{Preliminary Results}

The primary goal of this study is to demonstrate the capabilities of the newly configured NASA Langley LSAWT for aerodynamic and acoustic testing of small propeller and UAS rotor configurations. The following sections document results in the form of small propeller CFD predictions and their incorporation into the expected LSAWT facility operational limits, and isolated UAS rotor hover measurements. The rotor measurements are further compared with data acquired in an anechoic chamber on the same tested rotor and with acoustic predictions performed using the Propeller Analysis System (PAS) of the NASA Aircraft NOise Prediction Program (ANOPP). ${ }^{9}$ 


\section{A. Propeller Simulations}

A series of preliminary computational fluid dynamics (CFD) simulations have been run on the propeller mentioned previously using OVERFLOW2, ${ }^{10,11}$ an unsteady Reynolds-averaged Navier Stokes (uRANS) solver. A summary of the simulation cases run thus far is provided in Table 4. As this table shows, the simulation cases span a range of freestream Mach numbers, advance ratios, propeller rotation rates, and angles of attack. The purpose of these cases is to provide a predicted envelope of propeller performance for a range of flight conditions within the testing capability of the LSAWT. Figure 13(a) provides the predicted mean thrust coefficients for the six different simulated advance ratio cases at a common angle of attack of $\alpha=0^{\circ}$. Note that these mean thrust levels are those for a single converged revolution of the propeller blades. Furthermore, the thrust data was fit with a second order polynomial

Table 4. Flight conditions of propeller CFD simulations.

\begin{tabular}{|cccr|}
\hline$M_{\infty}$ & $\Omega(\mathrm{RPM})$ & $J$ & $\alpha\left(^{\circ}\right)$ \\
\hline 0.000 & 5866 & 0.000 & 0 \\
0.059 & 5866 & 0.059 & 0 \\
0.092 & 5866 & 0.717 & $0,3,9$ \\
0.118 & 5866 & 0.915 & 0 \\
0.123 & 4800 & 1.173 & 0 \\
0.132 & 4000 & 1.509 & 0 \\
\hline
\end{tabular}
regression that yielded a determination coefficient of $R^{2}=$ 0.9997.

The LSAWT open-jet performance data discussed previously is now used to provide propeller operational limits encompassing propeller thrust and size requirements. Utilizing an actuator disk model approach developed in Ref. 8 to account for core flow contraction caused by the propeller, the following relationship may be used to establish propeller performance bounds for an open-jet facility:

$$
\frac{C_{T}}{J^{2}}<\frac{\pi}{8}\left(\frac{D_{p}^{2}-D_{b}^{2}}{D_{p}^{2}}\right)\left\{\left[\frac{2 D_{s}^{2}}{D_{p}^{2}-D_{b}^{2}}-1\right]^{2}-1\right\},
$$

where $D_{s}$ is the diameter of the streamtube at the nozzle exit that contracts to the propeller diameter at the disk plane. An additional criterion for this streamtube diameter may be defined based on the LSAWT core flow reduction behavior described in the previous section. For example, the core flow measurement position at $x / D_{\text {nozzle }}=0.855$ corresponds to the desired axial position of the propeller disk plane for microphone array line-of-sight requirements. From the data in Fig. 6, the mean core flow diameter at this axial location is found to be approximately $80 \%$ of the inlet nozzle diameter. An additional margin of $30 \%$ of $D_{\text {nozzle }}$ between propeller tip and shear layer is also incorporated into this criterion in order to eliminate the need for empirical correction factors. ${ }^{12}$ Therefore, an upper limit propeller streamtube diameter may be defined as

$$
D_{s, \max }=0.80 \times 0.70 \times D_{\text {nozzle }}=0.56 D_{\text {nozzle }} .
$$

Inserting Eq. 4 into Eq. 3 and computing over a range of propeller diameters provides an upper limit propeller thrust performance capability for testing in the LSAWT.

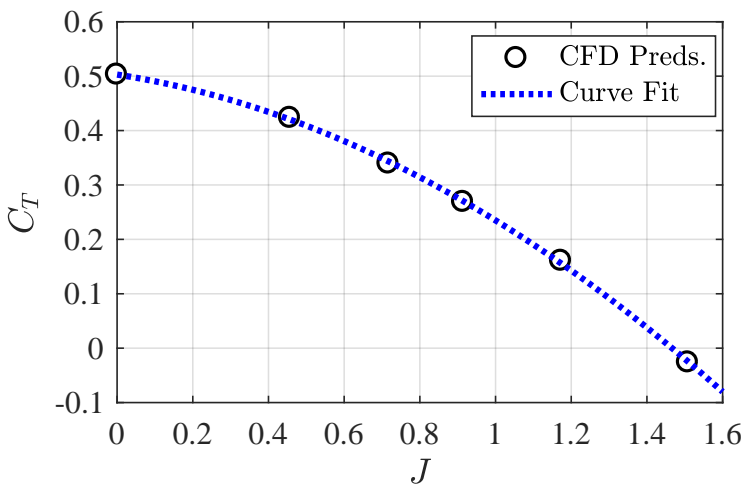

(a) $C_{T}$ Predictions $\left(\alpha=0^{\circ}\right)$

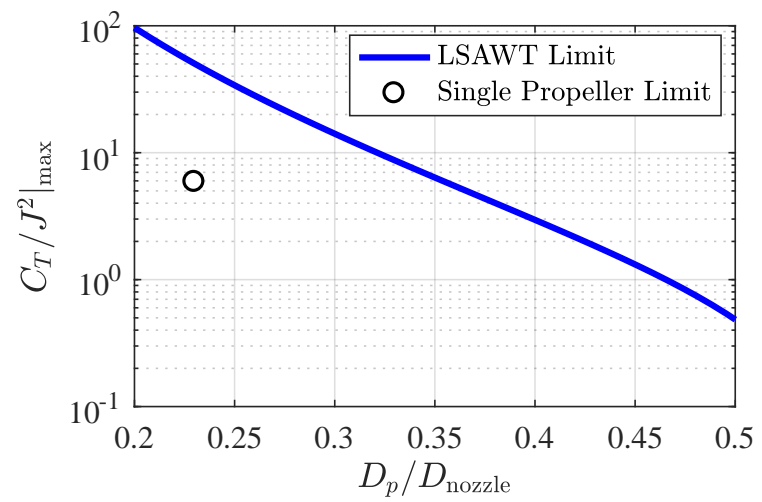

(b) LSAWT Propeller Testing Capabilities

Figure 13. Single propeller thrust coefficient predictions and upper-end predicted testing limits applied to LSAWT propeller operational curve (Eq. 3). 
The curve fit of Fig. 13(a) was then used to determine an estimate of the upper-end limit of the propeller in terms of $C_{T} / J^{2}$ and related to Eq. 3. Previous testing of the full-scale propeller under investigation has identified a rotation rate envelope of $3000 \leq \Omega \leq 7200$ RPM. This envelope coupled with the LSAWT current freestream velocity range capability documented in Table 1 yields a propeller advance ratio envelope of $0.28 \leq J \leq 2.15$. Relating the lower limit of this advance ratio envelope back to the $C_{T}$ prediction curve fit yields a predicted upper limit of $C_{T} /\left.J^{2}\right|_{\max } \approx 5.87$. This value for the corresponding propeller diameter relative to the LSAWT nozzle diameter, $D_{p} / D_{\text {nozzle }}$, is provided in Fig. 13(b) along with the modeled LSAWT propeller limit trend from Eqs. 3 and 4. As this figure shows, the propeller under investigation is predicted to fall well under the LSAWT propeller operational limit. For the case of three reduced-scale propellers of the same geometry as the single full-scale one, the upper limit of $C_{T} /\left.J^{2}\right|_{\max }$ is expected to remain constant under the assumptions of common Reynolds number behavior and common tip Mach numbers between full-scale and reduced-scale propellers. Therefore, the only parameter that would change is $D_{p \text {,eff }} / D_{\text {nozzle }}$, where $D_{p \text {,eff }}$ would represent an effective (or hydraulic) diameter of the combined disk area occupied by the three propellers. This analogy could be misleading, however, because it does not account for additional considerations including the asymmetric radial extents of the propeller disks or the turbulence levels near the periphery of the mean-measured core flow region. Surveys of the flow field both forward and aft of the propeller disks will be required in order to identify the extent of the LSAWT core flow contraction for different propeller thrust conditions. Therefore, identification of LSAWT operational limits for multiple propeller configurations is left for future work.

Acoustic predictions have also been performed by inputting the CFD-computed unsteady pressures of the propeller blade surfaces into the PSU-WOPWOP code, ${ }^{13}$ a Ffowcs Williams and Hawkings (FW-H) solver. This CFD-based acoustic prediction process is referred to as OF2-PSW. These predictions are useful to get an initial indication of expected facility signal-to-noise ratio (SNR). Figure 14 provides sample OF2-PSW acoustic predictions of the propeller rotating at $\Omega=5866 \mathrm{RPM}(97.77 \mathrm{~Hz})$ subjected to a $M_{\infty}=0.09$ freestream flow for a flyover observer location of $\theta_{o}=90^{\circ}$ relative to the forward flight direction. Note that due to the periodic nature of the CFD and thus, acoustic predictions, only the deterministic (or tonal) acoustics are predicted and are in the form of harmonics of the blade passage frequency (BPF). In this case, BPF $=N_{b} \times \Omega=488.83 \mathrm{~Hz}$, where $N_{b}=5$ blades. The two predictions shown are for propeller angles of attack of $\alpha=0^{\circ}$ and $9^{\circ}$. Also shown in this figure is an acoustic spectrum of the LSAWT empty test section for the same freestream flow conditions at an equivalent observer location. As the results show, there is a SNR of at least $10 \mathrm{~dB}$ for the first two BPF harmonics at $\alpha=0^{\circ}$ and for the first four harmonics at $\alpha=9^{\circ}$.

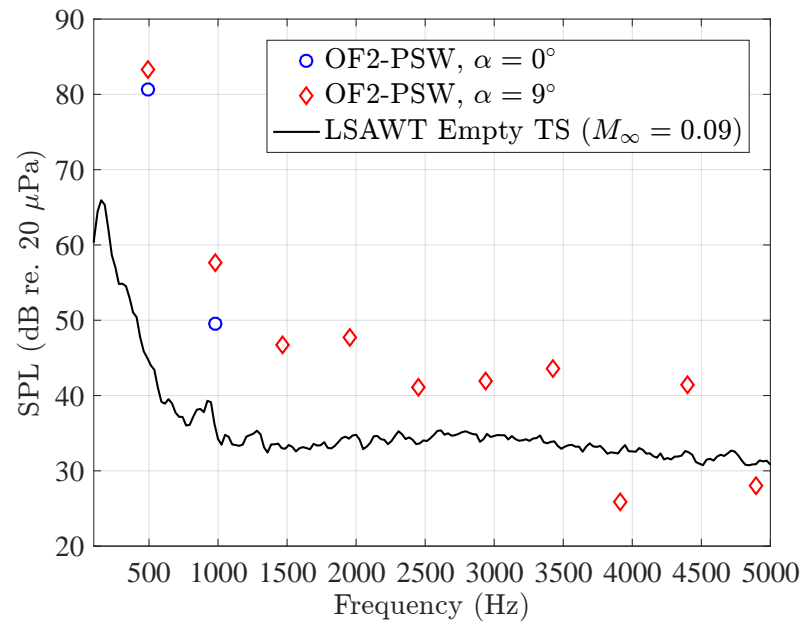

Figure 14. Deterministic noise prediction spectra of five-bladed propeller in a flyover configuration with comparison to experimental empty test section acoustic measurement. Note that empty test section spectrum is plotted with a frequency resolution of $\Delta f=25.6 \mathrm{~Hz}$.

\section{B. UAS Isolated Rotor Hover Measurements}

As an initial gauge of the performance of the LSAWT for small UAS performance and acoustic measurement capabilities, a single rotor representative of small rotary-wing UAS was analyzed. This rotor was also selected 
for testing since it had undergone similar hover performance and acoustic testing in the Structural Acoustics Loads and Transmission (SALT) anechoic chamber. ${ }^{10,14}$ Images of the test setups in the two respective facilities are provided in Fig. 15. The rotor was mounted in a propeller orientation within the LSAWT test section, which allowed for the wake to develop and convect downstream into the diffuser of the tunnel. This configuration reduced the possibility of measurement contamination due to wake flow recirculation within the test cell. The SALT facility setup, meanwhile, consisted of the rotor mounted in a vertical orientation and positioned in the middle of the anechoic chamber. Five microphones were utilized in the SALT facility experiments (labeled M1-M5 in Fig. 15), that spanned a range of elevation $(\theta)$ and azimuthal $(\phi)$ angles at a common radial distance of $10 R(R=190.5 \mathrm{~mm})$ from the rotor hub. The rotor hub was positioned

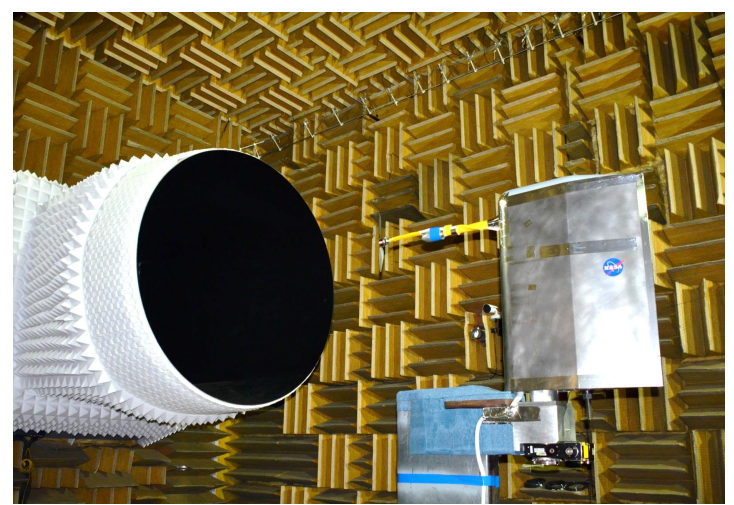

(a) Rotor and model test stand in LSAWT

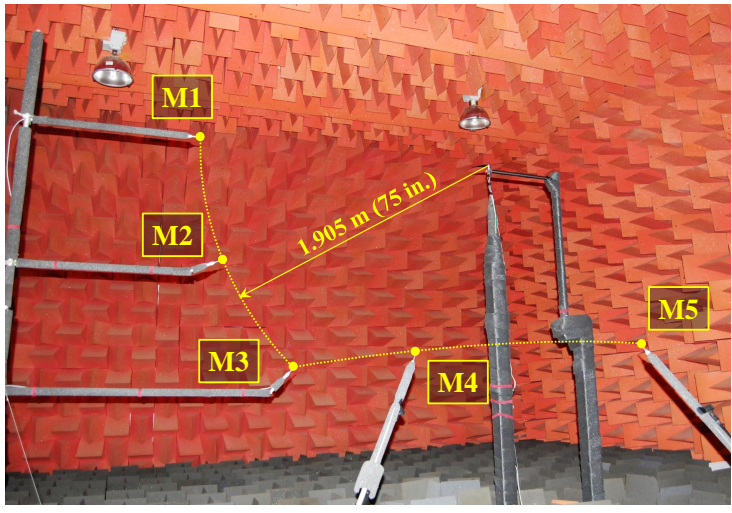

(c) SALT facility measurement setup

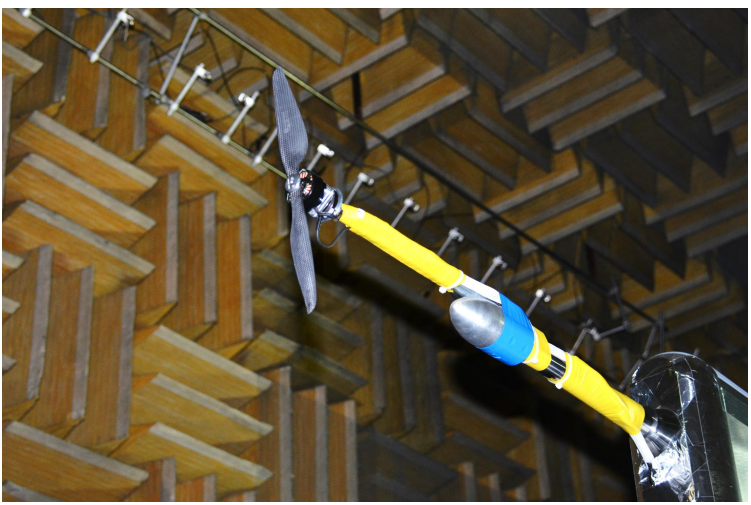

(b) Close-up of rotor-motor assembly in LSAWT

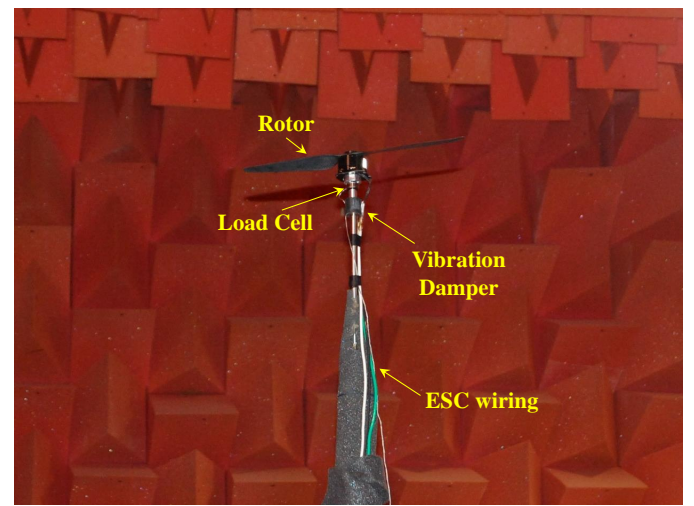

(d) Close-up of rotor-motor assembly in SALT facility

Figure 15. Single UAS rotor hover measurement setup in LSAWT and SALT anechoic chamber facilities.

along the centerline of the LSAWT inlet nozzle at a downstream location of $x / D_{\text {nozzle }}=0.65$. The linear microphone array elements are oriented such that they are pointed at the rotor hub. The plane of the rotor is approximately $5 R$ upstream of the leading edge of the MTS airfoil fairing, also in an attempt to mitigate noise contamination due to wake impingement and recirculation. Static force and moment measurements were made using an ATI-IA Mini-40 multi-axis load cell that was mounted directly behind the rotor-motor apparatus. The rotor is driven by a 24-pole brushless motor, powered by a 40 -amp electronic speed controller (ESC).

\section{Static Thrust Measurements}

Rotor hover performance measurements were obtained using the multi-axis load cell using two methods. The first method was a transient one in which the ESC was set to gradually increase the rotation rate of the rotormotor assembly, while simultaneously acquiring the load data. This method is implemented for quantifying the mean performance of the rotor over a broad range of rotation rates. The second method was such that the load cell data were acquired synchronously with the acoustic data for a given rotor rotation rate. Each of these data runs were preceded by a static run intended to serve as a load cell tare condition. Each run 
was separated by a five minute period to allow the load cell to re-acclimate to a steady-state condition. This second method of data acquisition is implemented for quantifying the dynamic loading associated with a given rotor operating condition. Figure 16 provides a comparison of rotor static thrust between the current LSAWT measurements to previous measurements made in the SALT anechoic chamber facility. As the data in this figure show, the thrust measurements compare very well between facilities, with the SALT facility data (and associated uncertainties) lying within the bias uncertainty bounds of the LSAWT data utilizing the multi-axis load cell. It is worth noting that the thrust data acquired in the SALT facility were done so using a single-axis load cell at specific rotor rotation rates (see Ref. 10), while the LSAWT data shown were acquired using the transient data acquisition method discussed previously. It is also worth noting that the LSAWT load cell data acquired using the second method yielded mean thrust and torque values within the bias uncertainty bounds (at the appropriate rotation rates) of the transient data of Fig. 16.

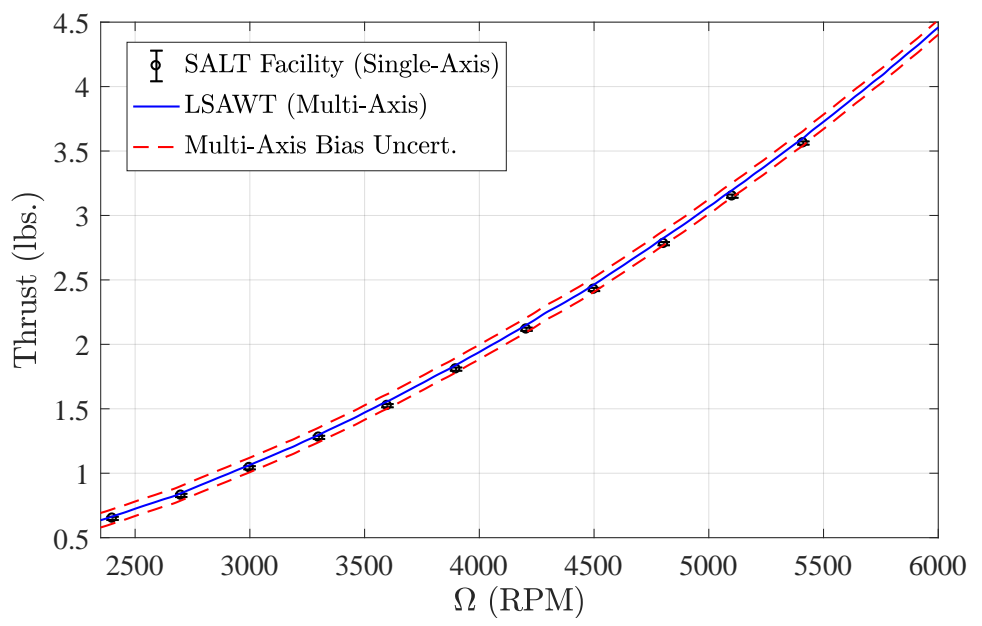

Figure 16. Static rotor thrust comparisons between LSAWT and SALT facility data sets. Note: LSAWT transient load cell data low-pass filtered at $10 \mathrm{~Hz}$.

\section{Acoustic Measurements}

Acoustic data acquired on the small rotor in hover in the LSAWT are compared both with previous experimental data acquired in the SALT facility along with predictions using PAS. PAS has been previously shown to provide acoustic predictions for small rotors in hover that compare very well with experimental measurements. ${ }^{10}$ Note that while PAS is traditionally used for modeling propellers in forward flight, it can be used to simulate "near" hover conditions by defining a small-amplitude climb velocity. The PAS results provided in this paper were generated by defining a rotor climb velocity of $U_{\infty}=1 \mathrm{~m} / \mathrm{s}$, which corresponds to an upper limit simulated advance ratio condition of $J_{\max } \leq 0.03$.

Acoustic spectra are compared between LSAWT and SALT facility data sets for observer elevation angles of $\theta=0^{\circ}$ (in the plane of the rotor) and $\theta=-45^{\circ}$ (below/behind the rotor plane) in Fig. 17. Note that the microphone time series data were processed identically between facilities: a total of twenty seconds of data were acquired at a sampling rate of $80 \mathrm{kHz}$, the first five seconds of which were FFT block-averaged using a Hanning window with $75 \%$ overlap. The resulting acoustic spectra have an autospectral random uncertainty of $u_{r_{\mathrm{SPL}}}= \pm 0.6 \mathrm{~dB}$. Due to the fact that the LSAWT linear array microphones are located considerably further away from the rotor hub than the SALT facility microphones, a far-field distance correction is applied to the LSAWT microphone data in order for a more direct comparison with the SALT microphone data. The acoustic spectra are seen to compare reasonably well between the two data sets for both observer angles. There are some differences in overall broadband spectral shape for $\theta=0^{\circ}$ between the two data sets; however, the spectral amplitudes are very low. This makes sense since broadband noise due to rotating blade self-noise is expected to be negligible in the plane of the rotor. ${ }^{15}$ The spectral attributes of greatest importance at this observer location are the tonal levels at the rotor BPF and the first several associated harmonics, which are seen to agree very well between the data sets. Focusing attention on the spectra measured at an observer angle of $\theta=-45^{\circ}$ reveals an expected increase in mid- to high-frequency broadband noise, the trends of which are in excellent agreement between the two facility data sets. In addition, the tonal harmonic content agrees well between the facilities; however, there are overall higher levels observed for the LSAWT data set. 


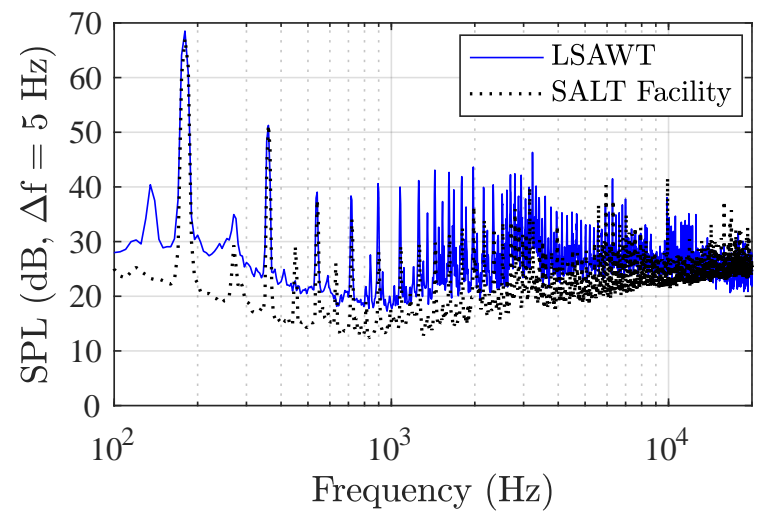

(a) $\theta=0^{\circ}$

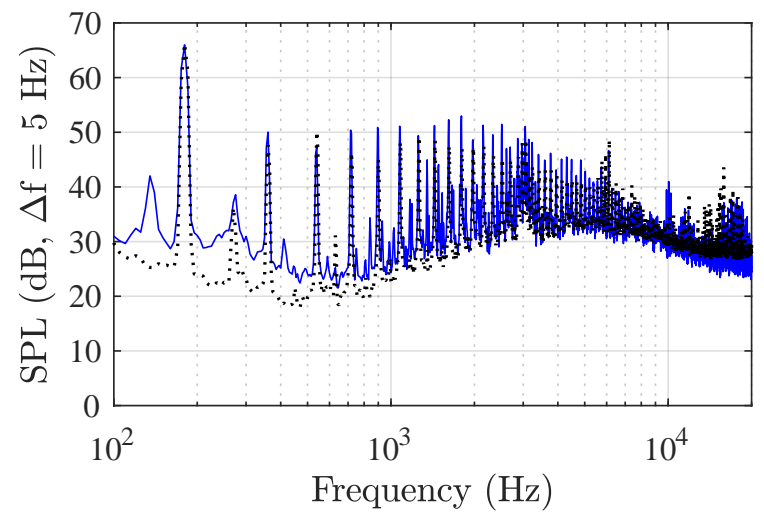

(b) $\theta=-45^{\circ}$

Figure 17. Acoustic spectral comparisons between LSAWT and SALT facility data sets (a) in the rotor plane and (b) below the plane of the rotor. Note: Data is for a rotor rotation rate of $\Omega=5400 \mathrm{RPM}$ (90 Hz); LSAWT spectra corrected to a distance of $10 R$ from the rotor hub.

This is believed to be related to the presence of occasional flow gusts experienced within the test cell, the wind tunnel inlet and exhaust of which were open during the time of testing.

Finally, BPF directivity comparisons are made between PAS predictions and LSAWT measurements for several different rotor rotation rates in Fig. 18. These rotation rates were selected for comparison since they correspond to BPFs that are near the anechoic cut-on frequency of LSAWT of approximately $200 \mathrm{~Hz}$. Note that in this figure, the PAS predictions are divided into their thickness and loading noise components, the sum of which yields the total noise at the BPF. SALT facility acoustic measurements for the two lower rotation rate conditions are also provided in this figure. The acoustic amplitudes of the SALT facility measurements are corrected using far-field spherical spreading to correspond to the LSAWT microphone locations. Furthermore, SALT facility data are only available for the two lower rotation rates shown in Fig. 18 due to limitations of the load cell used in the experiments. As the results show, there

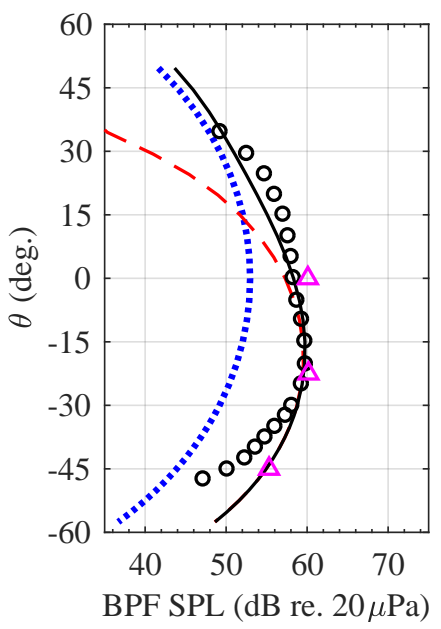

(a) $\Omega=4800 \operatorname{RPM}(\mathrm{BPF}=160 \mathrm{~Hz})$

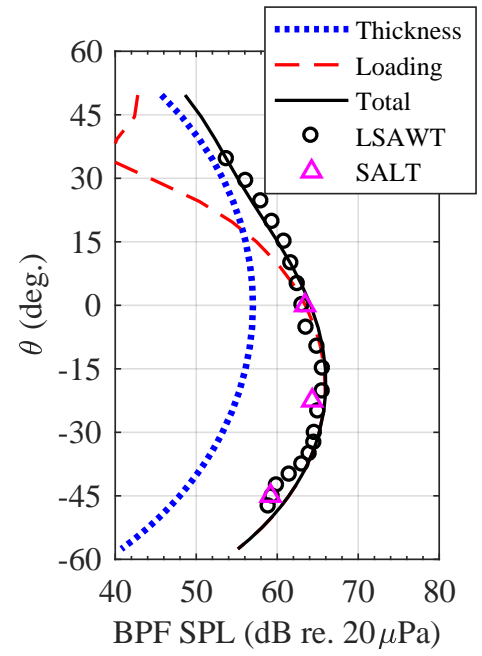

(b) $\Omega=5400 \mathrm{RPM}(\mathrm{BPF}=180 \mathrm{~Hz})$

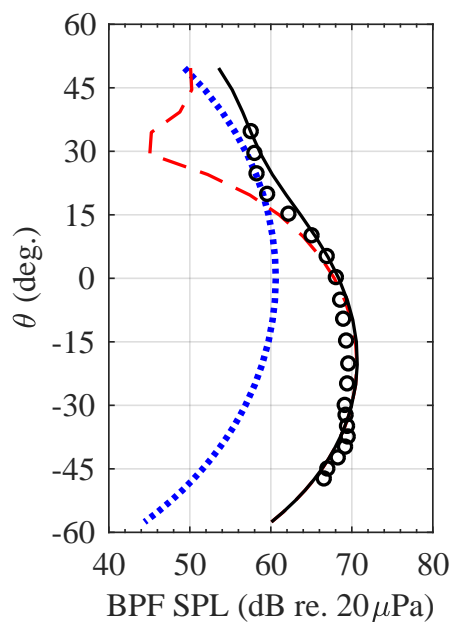

(c) $\Omega=6000 \mathrm{RPM}(\mathrm{BPF}=200 \mathrm{~Hz})$

Figure 18. BPF directivity comparisons between PAS predictions, LSAWT measurements, and SALT facility measurements for different rotor rotation rates. Note: SALT facility acoustic data corrected using spherical spreading to match LSAWT microphone locations.

is overall good agreement between the data sets, with better agreement occurring between PAS and the LSAWT measurements for the two highest rotation rate cases shown. An encouraging observation is how the LSAWT data capture the increasingly apparent transition from thickness to loading noise $\left(\theta \approx 15^{\circ}\right)$ for 
increasing rotation rates, as evidenced by the noise component breakdowns provided by PAS. Directivity discrepancies between PAS and LSAWT measurements for the two higher rotation rates are within $\pm 2.5 \mathrm{~dB}$, while that for the lower rotation rate exceeds $5 \mathrm{~dB}$ at an elevation angle of $\theta=-47.75^{\circ}$. This may be due to reflections from the wall-mounted wedges at this frequency. Note that the reliability of the PAS predictions at this low rotor rotation rate is reinforced by the good agreement with the SALT measurement at $\theta \approx-45^{\circ}$. It is important to note that the LSAWT microphones are mounted an average distance of $0.49 \mathrm{~m}$ from the acoustic wedge tips, which is approximately half of the distance between the microphones and wedge tips in the SALT facility measurements. Treating this as a 1/4-wavelength yields a notional cut-on frequency of $175 \mathrm{~Hz}$. This appears to be a reasonable approximation of the low-frequency capability of LSAWT based on the BPF directivity results of Fig. 18. In other words, while it appears that the LSAWT has the ability to measure the appropriate directivity trends associated with rotor- and/or propeller-generated tonal acoustics below this cut-on frequency, caution should be used in quantitative comparisons at frequencies below the notional cut-on frequency of approximately $175 \mathrm{~Hz}$.

\section{Conclusions and Future Work}

In this paper, the recent modifications made to the NASA Langley LSAWT for the purposes of small propeller and rotor testing were discussed. Furthermore, flow-field and acoustic characterizations of the open-jet test section were conducted. The goal of these characterizations is to identify the testing limits - in terms of rotor size, performance, and characteristic frequency ranges - of the facility. Preliminary simulation results of a full-scale isolated propeller have aided in identifying the performance limitations of the LSAWT facility, which will be verified experimentally in the near future. Furthermore, tests of a small isolated rotor operated at an equivalent hover condition across a range of rotor rotation rates were conducted and compared with acoustic predictions using a moderate fidelity blade element analysis technique and with previous experimental measurements made in an anechoic chamber. Static thrust measurements made in the LSAWT are in excellent agreement with measurements made in the SALT facility on the same rotor. Acoustic directivity measurements of the rotor in the LSAWT identified deviations in predicted behavior at characteristic frequencies below the approximated cut-on frequency of the facility. Rotor BPF directivity measurements in LSAWT were found to agree well with acoustic predictions for frequencies above the estimated cut-on frequency based on current microphone-acoustic wedge proximities.

In the immediate future, experimental performance and acoustic measurements will be made on the fullscale five-bladed propeller of which simulations were performed in this paper. The goals of these experiments will be to confirm the hypothetical propeller operational limits of the LSAWT as well as to validate CFD and acoustic predictions of the propeller across a range of flight conditions. Forward flight testing of both single rotor-copter arm and full quadcopter vehicle configurations are also planned. Furthermore, testing of scaled propellers is planned in both a multi-propeller and propeller-wing setup for characterization of respective propeller-propeller and propeller-wing interaction noise mechanisms.

\section{Acknowledgments}

The authors would like to acknowledge Mr. John Swartzbaugh and Stanley Mason of the Jet Noise Laboratory at NASA Langley Research Center for their tireless efforts involving facility conversion, test setup, and data acquisition. The authors would also like to acknowledge Pieter Buning of the Computational Aerosciences Branch and Douglas Nark of the Structural Acoustics Branch at NASA Langley for providing propeller aerodynamic and acoustic prediction data. Funding for this work is being provided by the NASA Transformative Tools and Technologies (TTT) project and the Design Environment for Novel Vertical Lift Vehicles (DELIVER) sub-project of the Convergent Aeronautical Systems (CAS) Project. Both of these projects are part of NASA's Transformative Aeronautics Concepts Program (TACP).

\section{References}

${ }^{1}$ NASA, New Aviation Horizons Initiative and Complementary Investments, Washington, D.C., 2016, Part of NASA Aeronautics Strategic Implementation Plan, Available at: http://www.aeronautics.nasa.gov/pdf/NASA-Aero-10-Yr-Plan-508.pdf.

${ }^{2}$ Doty, M. J., Quinto, P. F., Hutcheson, F. V., Haskin, H. H., Witte, D. W., and Smith, D. G., "NASA Langley Aeroacoustic Wind Tunnel Capability Moving Forward," 31st AIAA Aerodynamic Measurement Technology and Ground Testing Conference, AIAA, Dallas, TX, 2015, Invited Talk. 
${ }^{3}$ Bruun, H. H., Hot-wire anemometry : principles and signal analysis, Oxford ; New York : Oxford Unversity Press, 1995.

${ }^{4}$ Lucas, N., Doty, M., Taubert, L., and Wygnanski, I., "Reducing the noise emanating from a twin jet nozzle using flexible filaments," Experiments in Fluids, Vol. 54, No. 4, 2013, pp. 1-10.

${ }^{5}$ Doty, M. J. and Haskin, H. H., "Acoustic Characterization of Compact Jet Engine Simulator Units," 19th AIAA/CEAS Aeroacoustics Conference, AIAA, Berlin, Germany, 2013, AIAA Paper 2013-2035.

${ }^{6}$ Stoll, A. M., Bevirt, J., Moore, M. D., Fredericks, W. J., and Borer, N. K., "Drag reduction through distributed electric propulsion," 14th AIAA Aviation Technology, Integration, and Operations Conference, Atlanta, GA, 2014, AIAA Paper 20142851.

${ }^{7}$ Borer, N. K., Patterson, M. D., Viken, J. K., Moore, M. D., Bevirt, J., Stoll, A. M., and Gibson, A. R., "Design and Performance of the NASA SCEPTOR Distributed Electric Propulsion Flight Demonstrator," 16th AIAA Aviation Technology, Integration, and Operations Conference, Washington, D.C., 2016, AIAA Paper 2016-3920.

${ }^{8}$ Block, P. J. W., Operational Evaluation of a Propeller Test Stand in the Quiet Flow Facility at Langley Research Center, Hampton, VA, 1982, NASA TM 84523.

${ }^{9}$ Nguyen, L. C. and Kelly, J. J., A Users Guide for the NASA ANOPP Propeller Analysis System, Hampton, VA, 1997, NASA CR 4768.

${ }^{10}$ Zawodny, N. S., Boyd Jr., D. D., and Burley, C. L., "Acoustic Characterization and Prediction of Representative , SmallScale Rotary-Wing Unmanned Aircraft System Components," AHS International 72nd Annual Forum, AHS International, West Palm Beach, FL, 2016.

${ }^{11}$ Nark, D. M., Jones, W. T., Boyd, D. D., and Zawodny, N. S., "Isolated Open Rotor Noise Prediction Assessment Using the F31A31 Historical Blade Set," 54th AIAA Aerospace Sciences Meeting, AIAA, San Diego, CA, 2016, AIAA Paper $2016-1271$.

${ }^{12}$ Glauert, H., "Airplane Propellers," Aerodynamic Theory: A General Review of Progress Under a Grant of the Guggenheim Fund for the Promotion of Aeronautics, Springer Berlin Heidelberg, Berlin, Heidelberg, 1935, pp. 169-360.

${ }^{13}$ Brentner, K. and Farassat, F., "Modeling aerodynamically generated sound of helicopter rotors," Progress in Aerospace Sciences, Vol. 39, April 2003, pp. 83-120.

${ }^{14}$ Grosveld, F. W., "Calibration of the Structural Acoustics Loads and Transmission Facility at NASA Langley Research Center," InterNoise 99, Fort Lauderdale, FL, 1999.

${ }^{15}$ Burley, C. L. and Brooks, T. F., "Rotor Broadband Noise Prediction with Comparison to Model Data," Journal of the American Helicopter Society, Vol. 49, No. 1, 2004, pp. 28-42. 